\title{
GELENEKLER, GÖRENEKLER VE KÜLTÜRÜN DEVİR PLANINA ETKİSİ1
}

Mehmet Akif ÇİNi 2

Mustafa Atilla ARICIOĞLU 3
Received Date (Başvuru Tarihi):

$27 / 03 / 2020$

Accepted Date (Kabul Tarihi):

Published Date (Yayın Tarihi):
$20 / 04 / 2020$

$25 / 06 / 2020$
$\ddot{O Z Z}$

Anahtar Kelimeler:

Aile İşletmesi

Devir Planı

Kültür

Gelenek ve Görenekler

JEL Kodları:

L20, L21, M10
Aile işletmelerinin ekonomik hayatlarına devam etmesi ülkelerin ekonomisi ve refahı açısından çok önemlidir. Ancak bu işletmelerin sürdürülebilirlik oranları çok düşüktür. Bu süreçte işletmelerin objektif ve rasyonel bir şekilde oluşturulmuş etkin bir devir planlarına olan ihtiyacı bilinen bir gerçektir. Bu nedenle çalışma gelenek, görenek ve kültürün işletmelerin devir planlarına etki edip etmediŏini ölçmek adına gerçekleştirilmiştir. Örneklem olarak Konya ilinde en az 25 yıl faaliyet göstermiş, hala aktif olarak ticari hayatına devam eden 260 işletme kullanılmıştır. Veri toplama aracı olarak anket kullanılmıştır. Elde edilen bulgular yapısal eşitlik modellemesi ile analiz edilmiş ve sonuç olarak gelenek ve göreneklerin kültürü, kültürün devir planlamasını ve gelenek ile göreneklerin kültür aracılığıyla devir planlamasına etki ettiği tespit edilmiştir. Ayrıca gelenek ve göreneklerin direkt olarak devir planlamasına etki etmediŏi bulunmuştur.

\section{THE EFFECTS OF TRADITIONS, CUSTOMS AND CULTURE ON THE}

\section{SUCCESSION PLANNING}

\section{ABSTRACT}

Keywords:

Family Business

Succession Planning

Culture

Customs and Traditions

JEL Codes:

L20, L21, M10
It is very important for the economy and welfare of the countries that family businesses continue their economic life. However, the sustainability rates of these enterprises are very low. In this process, it is a well-known fact that businesses need an effective objective and rational succession planning. For this reason, this study was carried out to measure whether traditions, customs and culture affect the succession planning of the enterprises. As a sample, 260 businesses that have been operating for at least 25 years and are still actively continuing their business life in the city of Konya were used. Survey was used as a data collection tool. The obtained findings were analyzed by structural equation modeling and as a result, it was determined that customs and traditions affected the culture, culture affected the succession planning and customs and traditions through culture affected the succession planning. It has also been found that traditions and customs do not directly affect succession planning.

\footnotetext{
${ }^{1}$ Bu çalışma, 2019 yılında Necmettin Erbakan Üniversitesi Bilimsel Araştırma Proje Koordinatörlüğünün (BAP) 181221002 numaralı araştırma projesi kapsamında gerçekleştirilmiştir. Bu nedenle etik kurul izni alınmasına gerek kalmamıştır.

2 Dr. Öğr. Üyesi, Selçuk Üniversitesi, mehmetakifcini@selcuk.edu.tr,

3 Prof. Dr., Necmettin Erbakan Üniversitesi, maaricioglu@gmail.com,

https://orcid.org/0000-0001-7619-978X

https://orcid.org/0000-0001-6477-832X
} 


\section{GİRIŞ}

Varlık gerekçeleri, ekonomilere kattığı değerler bağlamında dikkate alındığında aile işletmelerinin, ülke ekonomilerinin gelişimi ve refahı açısından çok önemli bir role sahip olduğu bilinmektedir. Bu bağlamda aile işletmelerinin sürdürülebilirliğinin sağlanması önemlidir. Bunun sağlanabilmesi için de yaşanan sorunların ve buna ilişkin çözüm yollarının bilinmesi, tartışılması ve araştırılması gerekir. Nitekim nesilden nesle geçişteki devir oranları incelendiğinde, aile işletmelerinin kan kaybettiği de bilinen bir gerçektir. Öyle ki tüm dünyada üçüncü neslin sonrası başarı olarak kabul edilirken, beşinci ve üstü neslin yönetiminde aktif bir şekilde ticari hayatına devam eden işletme sayısı araştırmalara konu olacak kadar azdır. Bu problemin neden oluştuğunu anlamak için literatür incelendiğinde, sorunu araştıran araştırmacıların genellikle kurumsal yapı, uygun iletişim ağı, aile anayasası, devir planı, kaynak dağılımı ve birden fazla sistemin olması konuları üzerinde yoğunlaştığı görülmektedir. Ancak devir planı, aile işletmelerinin sürdürülebilirliğinin sağlanmasında en çok araştırılan ve etkileşim alan konuların başında gelmektedir. Çünkü bir işletmenin devir planına sahip olması ve bu planı uygulamaya sokmasının yönetimin devri ve işletmenin sürdürülebilir kılınmasına olumlu bir etkisinin olduğu literatürde genel olarak kabul edilmiştir.

Bu çalışmada ise devrin farklı bir yönü ele alınarak işletmenin etkileşim içinde olduğu hatta varlığını tanımlarken önemli bir belirleyici olan gelenekler/görenekler ile kültürün, devir planını etkileyip etkilemediği incelenmiştir. Ayrıca bu unsurların aile işletmelerinin sürdürülebilirliğinde ki etkisi de yorumlanmıştır. Çalışmanın bu açıdan literatüre katkı sağlayacağı öngörülmektedir.

\section{KAVRAMSAL ÇERÇEVE}

\subsection{Aile İşletmeleri ve Önemi}

İnsanın varlığı ile birlikte var olan ancak 20. yüzyıl sonlarında dünya ekonomisindeki rolü anlaşılmaya başlanan aile işletmelerinin, literatürde genel kabul görmüş bir tanımı bulunmamaktadır. Her araştırmacı bu kavramın sahip olduğu bir özelliği dikkate almış ve bu özellik üzerinden kavramı tanımlamıştır. Ancak hemen hemen her tanımın içinde bu sistemin mülkiyet yapısı, yönetimi veya sürdürülebilir 
olması konularından en az birisine değinilmiştir. Nitekim Chua, Chrisman ve Sharma (1999, s. 25), tüm tanımları kapsayacak bir tanım geliştirdiklerini belirtmişler ve aile işletmelerini;

“Nesilleri arasında sürdürülebilir olacak şekilde, aynı ailenin üyeleri veya sayıca az ailelerin baskın bir koalisyon oluşturarak, işletmenin vizyonunu şekillendirme ve sürdürme niyetiyle hükmettiği ve\veya yönettiği işletmelerdir" şeklinde tanımlamışlardır.

Kavramsal olarak bir uzlaşma olmasa da, aile işletmelerinin her ülke ekonomisi için çok önemli olduğu herkes tarafından kabul edilen yadsınamaz bir gerçektir. Nitekim Dünya'da her 2 işletmeden 1'i, Amerika'da her 10 işletmenin 9'u, Avrupa'da ise her 10 işletmenin ortalama 7'si aile işletmelerinden oluşmaktadır. Ülkemizde de durum farklı değildir. Her 10 işletmenin 9'u aile işletmesidir. Ayrıca bu işletmeler Amerika'da Gayri Safi Milli Hasılanın \% 64'ünü üretirken, bu oran ülkemizde \% 90'dır (EFB, 2018; Deloitte, Akbank, Taider, İstanbul Sabanc1 Üniversitesi, 2016; Pwc, 2016; Score, 2018). Bu nedenle bu işletmelerin sürdürülebilir olması ve buna ilişkin devri planlaması birçok unsurdan daha yaşamsaldır.

\subsection{Devir Planı}

Aile işletmelerinde devir planı, Sharma, Chua ve Chrisman (2000, s. 233) tarafından; "Yönetimin kontrolünün bir aile üyesinden diğerine devredildiği açık süreç" şeklinde tanımlanmıştır. Bjuggren ve Sund'a (2001, s. 11) göre, her aile işletmesi bir gün işletmenin devir edilmesi sorunu ile karşı karşıya kalacaktır. Bu süreçte işletme ya daha genç bir aile üyesine devredilecek ya da aile üyesi olmayan bir kişiye satılacaktır. Bu iki seçenekten birisi gerçekleşmediği zaman, işletme kapanma riski ile karşı karşıya kalacaktır. Christensen'e (1953, s. 19) göre, "İşletmenin hayatta kalabilme yeteneği, finansal dayanaklılığına, tesis ve ekipmanlarının yeterli olmasına, ürünlerinin rekabetçi pozisyonuna, işletmenin güncel pozisyonuna ve bunlarla ilgili olabilecek birkaç faktöre bağlıdır. Ancak hayatta kalmak ağırlıklı olarak yönetim yeteneklerine ve liderlik için belirli bir plan dâhilinde seçilmiş ve yetiştirilmiş halefe bağlıdır". Benzer şekilde Trow'da (1961, s. 234), bir işletmenin sürdürülebilirliğinin ve refahının sağlanmasında devir planının 
hayati bir önem taşıdığını ifade etmiştir. Bu bağlamda devir planlamasının işletmenin sürdürülebilirliğinin sağlanmasına olumlu etki eden unsurlardan birisi olduğu ifade edilebilir. Aksi durumda hem işletmelerin varlığ ekonomileri olumsuz etkilenebilmektedir (Sharma ve diğerleri, 2000, s. 234).

\subsection{Kültür, Gelenek ve Görenek}

İşletmelerin sürdürülebilir olmaları ve gelecek nesillere devir edilebilmeleri konusunda çok fazla araştırma yer almaktadır. Ancak bu süreçte kültür ve kültürün alt faktörlerinin bu sürece nasıl etki ettiğini araştıran çok fazla çalışma bulunmamaktadır. Oysa ki kaos kuramına göre, yöneticilerin öngörülerine göre inanca dayalı paradigmalar iflas etmiş ve yerini esnek, akıcı ve çevresel değişimlere anında ayak uydurabilen bir yönetim felsefesine bırakmıştır (Şimşek, 2001, s. 25). Schein, örgüt kültürünü, "bir grubun dişa uyum sağlama ve iç bütünleşme sorunlarını çözmek için oluşturduğu ve geliştirdiği belirli düzendeki temel varsayımlar" olarak tanımlamıştır (akt. Eren, 2001, s. 135). Bu nedenle bir işletmenin sürdürülebilir olması için belirlenen unsurlar ile devir planının yanı sıra, çevresinde ki gelişmelere karşı esnek olabilmesi ve kültürün bu süreçteki etkisinin çok önemli olduğu ifade edilebilir. Ayrıca örgüt teorisinin anlaşılması açısından, örgüt yapısının, dizaynının, örgüt kültürü ve kültürün alt boyutlarının (gelenek ve göreneklerin) analiz edilmesi çok kritiktir.

Kültür kavramının, Latince kökten gelen ve toprağın sürülmesini baz alan birkaç anlamı vardır. Çoğu batı dillerinde ise kavram, edebiyat, sanat ve eğitim gibi bir ülkenin kalkındığını gösteren unsurların bir sonucu ve medeniyet veya kusursuz düşünce anlamlarına gelmektedir (Hofstede, 2010, s. 5). Godwyn ve Gittell'e (2011, s. 311) göre, "kültür, insanların deneyimleri yorumlamak ve sosyal davranışlar üretmek için kullandıkları bilgidir. Bu bilgi, değerler ile tutumları oluşturur ve insan davranışlarına etki eder." Çünkü kültür kalıtsal veya biyolojik temelli değildir, öğrenmeye dayalı ortak bir olgudur, o kültürün öğrenildiği yerde yaşamış ve yaşayan insanlarla arasında yani nesiller arasında paylaşılmaktadır, insanın bir şeyi simgeleme, kullanma, değişim ve adapte olma kapasitesine dayanır. Ayrıca bir yapısı vardır ve bütünleşmiş̧ir; bir kısımdaki bir değişiklik başka bir kısımdaki değişiklikleri 
getirecektir. Sonuç olarak kültür bir örgütün veya onun bir parçasının en derin yapisidir. (Luthans ve Doh, 2012, s. 124; Hofstede, 2010, s. 5; Godwyn ve Gittell, 2011, s. 311). Bu nedenle bu derin yapının unsurlarını açıklayarak, gelenek ve görenek ile ilişkisini ifade etmek çalışmanın kavramsal çerçevesi açısından önemlidir.

Schabracq'a göre (2007, s. 17) kültür; efsaneleri, kavramları, inançları ve düşünceleri içeren mitoloji, gelenek ve göreneklerden etkilenen kurallar ile normlar ve neyin gerçek olduğu/olmadığı, neye katılması/katılmaması, ne ile meşgul olması/olmaması gerektiğinin ayırt edilmesini sağlayan ve kuralların sınırlarını belirleyen varsayımlardan oluşmaktadır.

Gelenek ve görenekler kültürün oluşturan katmanlarda yer alır ve kural ve normlar aracılığıyla insanların nasıl davranması gerektiğini anlamalarına yardımcı olmaktadir (Luthans ve Doh, 2012, s. 127). Bu nedenle gelenek ve görenekler, kültürün oluşmasında etkili bir rol üstlenmektedir. Ancak bir kültürün tamamen gelenek ve göreneklerden oluştuğunu söylemek de çok yanlış bir yaklaşım olur. Çünkü kültürün oluşmasında gelenek ve göreneklerin haricinde çok farklı unsurlarda (eğitim, küreselleşme, din vb.) vardır.

Türk Dil Kurumuna (2020) göre gelenek; “Bir toplumda, bir toplulukta eskiden kalmış olmaları dolayısıyla saygın tutulup kuşaktan kuşağa iletilen, yaptırım gücü olan kültürel kalıntılar, alışkanlıklar, bilgi, töre ve davranışlar, anane, tradisyon" şeklinde, görenek ise; "Bir şeyi eskiden beri görüldüğü gibi yapma alışkanlığı, âdet" şeklinde tanımlanmıştır. Karadeniz'e göre (2007, s. 37), kavramlar etimolojik olarak incelendiğinde, İngilizce, Arapça ve Türkçe dilinde intikal etmek ve süreklilik anlamalarını taşımakta ve benzer bir köke sahip oldukları görülmektedir. $\mathrm{Bu}$ bağlamda gelenek ve görenekler aracılı̆̆ıla insanların kendi izlerini sonraki nesillere aktardiğı ve bu izlerin sonraki nesillerin kültürünün oluşmasında etkili olduğunu söylemek mümkündür. Ancak her örgüt veya topluluğun kendine has farklı izlerinin olması, örgütten örgüte veya toplumdan topluma kültür farklılıklarının oluşmasına neden olmaktadır. Dolayısıyla çalışmanın yapıldı̆̆ı ülke kültürüyle ilgili bilgilere yer vermek gerekmektedir. Literatürde kültür açısından ülkemizle alakalı yapılmış ve genel kabul görmüş çalışmalardan birisi Hofstede ve 
arkadaşları tarafından 1984 yılında gerçekleştirilmiştir. Bu çalışma 76 ülkede, IBM şirketi çalışanları aracıllğıyla gerçekleştirilmiş ve ülkelerin kültürel farklılıkları öncelikle 4 temel faktör altında incelenmiştir. Daha sonra çalışmaya 2 temel faktör daha ilave edilse de ülkemiz açısından bir değerlendirme yapılmamıştır. Bu sebeple ülkemizle alakalı 4 temel faktör kapsamında değerlendirmelere yer verilmiştir. Bu çalışmada, toplumlar güç aralığı, bireysellik/kolektivizm, maskülen/dişil ve belirsizlikten kaçınma temel faktörleri açısından değerlendirmiştir. Tablo 1'de Hofstede ve diğerlerinin (2010) yaptığı çalışma kapsamında, 4 temel faktör çerçevesinde toplumların iş, işyeri, çalışma, eğitim, motivasyon, örgüt yapıları ve ilişkileriyle alakalı bilgilere yer verilmiştir. Çalışmaya göre ülkemiz, güç aralığı yüksek, kolektivist, dişil ve belirsizlikten yüksek derecede kaçınan kültür özellikleri göstermektedir. Hosftede ve diğerlerine göre (2010, s. 78- 219) tarım kökeni olan toplumlar kolektivist bir yapıya sahiptir. Bir ülke kolektivist olmanın yanı sıra belirsizlikten kaçıyor ve güç aralığı da yüksek ise, o ülkede kurallar örtük ve köklü geleneklere dayanmaktadır. Nitekim ülkemiz için benzer yorumlar yapılabilir. 


\title{
Tablo1. Toplumların İş, İşyeri, Çalışma, Eğitim, Motivasyon, Örgüt Yapıları ve
}

\author{
İlişkileri Açısından Farklılıkları
}

\begin{tabular}{|c|c|c|c|c|c|c|c|}
\hline \multicolumn{8}{|c|}{$\begin{array}{l}\text { Güç aralığı, "bir toplumun bağllık ilişkileri hakkında bilgi vermektedir. Güç aralığının düşük olduğu toplumlarda, patronla astlar } \\
\text { arasında karşlıklı ve sınırlı bir bağımlılık vardır. Bu toplumlarda bir ast, üstleriyle kolayca iletişim kurabilmekte, bir konu hakkında } \\
\text { istişare edebilmekte ve bazı durumlarda fikir ayrılıkları yaşanabilmektedir. Güç aralığının yüksek olduğu toplumlarda ise, astların } \\
\text { üstlerine karşı bağllıkları vardır. Otokratik ya da paternalist bir anlayışı hâkim olduğu bu toplumlarda astlar üstlere karşı ya tam } \\
\text { manasıyla bağlllığı tercih eder, ya da tamamıyla bu bağllığa karşıdır. Dolayısıyla bu iki anlayış arasında her zaman bir kutuplaşma } \\
\text { söz konusudur. Bu toplumlarda genellikle bir ast, üstleriyle rahatça iletişim kuramaz, onlarla istişare edemez ve fikir ayrılıkları } \\
\text { yaşanmaz (s. 61)." } \\
\text { Bireysellik, "bir toplum içindeki bireylerin birbirleri ile olan bağlarının gevşek olduğu durumlarda geçerlidir. Bu tarz toplumlarda } \\
\text { bireyler sadece kendi veya yakın ailesinin çıkarlarını düşünerek hareket eder. Bu durumun tersi kolektivizm ise doğumundan } \\
\text { itibaren insanların bir gruba entegre edildiği ve sorgusuz sadakatleri karşlığında bu grubun korumasını ve ayrıcalıklarına sahip } \\
\text { olduğu durumlarda geçerlidir (s. 92)." } \\
\text { "Bir toplumun maskülen olarak ifade edilebilmesi için, o toplumda bireylerin cinsiyete bağlı rollerinin açık bir şekilde ayrışması } \\
\text { gerekmektedir. Örneğin maskülen toplumlarda erkekler sert, iddialı ve maddi başarıya odaklanırken, tam tersi kadınlar ise daha } \\
\text { hassas, mütevazı ve yaşam kalitesine odaklanırlar. Dişil toplumlarda ise cinsiyete bağlı roller örtüşmektedir. Yani erkek veya kadın } \\
\text { daha mütevazı, hassas ve yaşam kalitesine beraber odaklanırlar (s. 140)." } \\
\text { "Belirsizlikten kaçınma, bir kültürün üyelerinin belirsiz veya bilinmeyen durumlar karşısında ne kadar tehdit altında hissettikleri } \\
\text { olarak tanımlanabilir (s.191)." }\end{array}$} \\
\hline \multicolumn{2}{|c|}{ Güç Aralığ1 } & \multicolumn{2}{|c|}{ Kolektivizm/Bireysellik } & \multicolumn{2}{|c|}{$\begin{array}{c}\text { Dişil/Maskülen } \\
\end{array}$} & \multicolumn{2}{|c|}{ Belirsizlikten Kaçınma } \\
\hline $\begin{array}{c}\text { Düşük } \\
\text { Toplumlar }\end{array}$ & $\begin{array}{l}\text { Yüksek } \\
\text { Toplumlar }\end{array}$ & Kolektivizm & Bireysellik & Dişil & Maskülen & Düşük & Yüksek \\
\hline $\begin{array}{l}\text { Organizasyon } \\
\text { içindeki } \\
\text { hiyerarşi rollerin } \\
\text { eşitsizliği } \\
\text { manasina } \\
\text { gelmektedir. }\end{array}$ & $\begin{array}{l}\text { Organizasyon } \\
\text { içindeki } \\
\text { hiyerarşi, } \\
\text { üstler ve astlar } \\
\text { arasındaki } \\
\text { varoluşsal } \\
\text { eşitsizliğin } \\
\text { yansımasıdır. }\end{array}$ & $\begin{array}{c}\text { Diploma } \\
\text { bireyin çok } \\
\text { daha saygın } \\
\text { üst gruplara } \\
\text { girmesini } \\
\text { sağlar. }\end{array}$ & $\begin{array}{l}\text { Diploma, } \\
\text { bireyin } \\
\text { ekonomik } \\
\text { servetini ve } \\
\text { kendisine } \\
\text { olan } \\
\text { saygisın } \\
\text { artırır. }\end{array}$ & $\begin{array}{l}\text { Aile olarak } \\
\text { yönetim } \\
\text { sezgilere ve } \\
\text { fikir } \\
\text { birliğine } \\
\text { bağlıdır. }\end{array}$ & $\begin{array}{c}\text { Aile olarak } \\
\text { yönetim kati } \\
\text { ve agresiftir. }\end{array}$ & $\begin{array}{l}\text { Daha fazla } \\
\text { işveren } \\
\text { değişikliği } \\
\text { ve kısa } \\
\text { servis } \\
\text { süresi } \\
\text { vardır. }\end{array}$ & $\begin{array}{l}\text { Daha az işveren } \\
\text { değişikliği, uzun } \\
\text { servis süresi ve } \\
\text { iş yaşam } \\
\text { dengesini } \\
\text { ayarlamak çok } \\
\text { zordur. }\end{array}$ \\
\hline $\begin{array}{c}\text { Âdemi } \\
\text { merkeziyetçilik } \\
\text { anlayış1 } \\
\text { popülerdir. }\end{array}$ & $\begin{array}{l}\text { Merkeziyetçili } \\
\text { k anlayış1 } \\
\text { popülerdir. }\end{array}$ & $\begin{array}{c}\text { Mesleki } \\
\text { hareketlilik } \\
\text { düşüktür. }\end{array}$ & $\begin{array}{c}\text { Mesleki } \\
\text { hareketlilik } \\
\text { yüksektir. }\end{array}$ & $\begin{array}{c}\text { Çatışmalar, } \\
\text { tarafların } \\
\text { ödün } \\
\text { verdiği } \\
\text { anlaşmalarla } \\
\text { çözümlenir. }\end{array}$ & $\begin{array}{l}\text { Çatışmalar, } \\
\text { güçlü olanın } \\
\text { kazanması } \\
\text { sonucu } \\
\text { çözümlenir. }\end{array}$ & $\begin{array}{l}\text { Kesinlikle } \\
\text { gerekli } \\
\text { olanlar } \\
\text { haricinde } \\
\text { daha fazla } \\
\text { kural } \\
\text { yoktur. }\end{array}$ & $\begin{array}{c}\text { İşe yaramasa } \\
\text { bile psikolojik } \\
\text { olarak çok fazla } \\
\text { kural } \\
\text { konulmuştur. }\end{array}$ \\
\hline $\begin{array}{c}\text { Denetimci } \\
\text { olarak çalışan } \\
\text { sayısı azdır. }\end{array}$ & $\begin{array}{c}\text { Denetimci } \\
\text { olarak çalışan } \\
\text { sayısı çoktur. }\end{array}$ & $\begin{array}{l}\text { Çalışanlar } \\
\text { grubun } \\
\text { çıarlarını } \\
\text { gözetecek } \\
\text { olan grup } \\
\text { üyeleridir. } \\
\end{array}$ & $\begin{array}{l}\text { Çalışanlar, } \\
\text { kendi } \\
\text { çıkarlarını } \\
\text { gözetecek } \\
\text { olan } \\
\text { kişilerdir. } \\
\end{array}$ & $\begin{array}{c}\text { Ödüller } \\
\text { eşitlik ilkesi } \\
\text { prensibine } \\
\text { göre } \\
\text { dağıtılır. }\end{array}$ & $\begin{array}{c}\text { Ödüller } \\
\text { adalet ilkesi } \\
\text { prensibine } \\
\text { göre } \\
\text { dağıtılır. }\end{array}$ & $\begin{array}{c}\text { Sadece } \\
\text { ihtiyaç } \\
\text { olduğund } \\
\text { a çok fazla } \\
\text { çalışılır. }\end{array}$ & $\begin{array}{c}\text { Psikolojik olarak } \\
\text { meşgul olmak } \\
\text { ihtiyacı vardır } \\
\text { ve çok çalışmak } \\
\text { içsel bir } \\
\text { dürtüdür. } \\
\end{array}$ \\
\hline $\begin{array}{l}\text { Ast ve üstlerin } \\
\text { maaşları } \\
\text { arasındaki fark } \\
\text { düşüktür. }\end{array}$ & $\begin{array}{l}\text { Ast ve üstlerin } \\
\text { maaşları } \\
\text { arasındaki } \\
\text { fark yüksektir. }\end{array}$ & $\begin{array}{c}\text { İse alım ve } \\
\text { terfi } \\
\text { kararları } \\
\text { bireyin dâhil } \\
\text { olduğu grup } \\
\text { dikkate } \\
\text { alınarak } \\
\text { verilir. } \\
\end{array}$ & $\begin{array}{c}\text { İse alım ve } \\
\text { terfi } \\
\text { kararları } \\
\text { sadece } \\
\text { kişinin } \\
\text { yetenekleri } \\
\text { ve kurallara } \\
\text { göre verilir. } \\
\end{array}$ & $\begin{array}{c}\text { Küçük } \\
\text { örgütler çok } \\
\text { daha } \\
\text { yaygındır ve } \\
\text { tercih edilir. }\end{array}$ & $\begin{array}{c}\text { Büyük } \\
\text { örgütler } \\
\text { daha } \\
\text { yaygındır ve } \\
\text { tercih edilir. }\end{array}$ & $\begin{array}{c}\text { Zaman } \\
\text { oryantasyon } \\
\text { için } \\
\text { gerekli bir } \\
\text { yapıdır. }\end{array}$ & Zaman paradır. \\
\hline $\begin{array}{c}\text { Yöneticiler } \\
\text { kendi } \\
\text { deneyimlerine } \\
\text { ve astlarına } \\
\text { güven duyar. }\end{array}$ & $\begin{array}{c}\text { Yöneticiler } \\
\text { denetimcilere } \\
\text { ve katı } \\
\text { kurallara } \\
\text { güven duyar. }\end{array}$ & $\begin{array}{l}\text { İşçi işveren } \\
\text { ilişkisi aynı } \\
\text { ailede } \\
\text { olduğu gibi } \\
\text { ahlaki } \\
\text { temellere } \\
\text { dayanır. }\end{array}$ & $\begin{array}{c}\text { İşçi işveren } \\
\text { ilişkisi aynı } \\
\text { iş } \\
\text { dünyasında } \\
\text { ki taraflarda } \\
\text { olduğu gibi } \\
\text { kontratlara } \\
\text { dayanır. } \\
\end{array}$ & $\begin{array}{c}\text { İnsanlar } \\
\text { yaşamak } \\
\text { için çalışır. }\end{array}$ & $\begin{array}{l}\text { İnsanlar } \\
\text { çalışmak } \\
\text { için yaşar. }\end{array}$ & $\begin{array}{l}\text { Belirsizlik } \\
\text { ve kaos } \\
\text { için belirli } \\
\text { bir } \\
\text { tolerans } \\
\text { payı } \\
\text { vardır. }\end{array}$ & $\begin{array}{c}\text { Önlemler ve } \\
\text { standardizasyona } \\
\text { ihtiyaç vardır. }\end{array}$ \\
\hline $\begin{array}{c}\text { Astlar, } \\
\text { üstlerinden } \\
\text { kendilerine } \\
\text { danışmasını } \\
\text { bekler. }\end{array}$ & $\begin{array}{c}\text { Astlar, } \\
\text { üstlerinden } \\
\text { kendilerine ne } \\
\text { yapması } \\
\text { gerektiğini } \\
\text { söylemesini } \\
\text { bekler. } \\
\end{array}$ & $\begin{array}{c}\text { Yönetim } \\
\text { grubu } \\
\text { yönetmektir. }\end{array}$ & $\begin{array}{c}\text { Yönetim } \\
\text { bireyleri } \\
\text { yönetmektir. }\end{array}$ & $\begin{array}{c}\text { Boş zamanın } \\
\text { olması para } \\
\text { kazanmaktan } \\
\text { daha } \\
\text { önemlidir. }\end{array}$ & $\begin{array}{c}\text { Para } \\
\text { kazanmak } \\
\text { boş zamanın } \\
\text { olmasından } \\
\text { daha } \\
\text { önemlidir. }\end{array}$ & $\begin{array}{c}\text { Genel } \\
\text { kültürüu } \\
\text { yüksek } \\
\text { olan } \\
\text { kimselere } \\
\text { ve ortak } \\
\text { görüşlere } \\
\end{array}$ & $\begin{array}{c}\text { Uzmanlara ve } \\
\text { teknik } \\
\text { çözümlere } \\
\text { inanırlar. }\end{array}$ \\
\hline
\end{tabular}




\begin{tabular}{|c|c|c|c|c|c|c|c|}
\hline & & & & & & inanırlar & \\
\hline $\begin{array}{l}\text { İdeal patron, işi } \\
\text { iyi bilen ve } \\
\text { demokrat } \\
\text { olandır. }\end{array}$ & $\begin{array}{l}\text { İdeal patron, } \\
\text { iyiliksever, } \\
\text { otokrat ve iyi } \\
\text { baba rolüne } \\
\text { sahip olandır. }\end{array}$ & $\begin{array}{c}\text { Astların } \\
\text { doğrudan } \\
\text { yaptığı } \\
\text { değerlendir } \\
\text { meler grup } \\
\text { uyumunu } \\
\text { bozmaktadır }\end{array}$ & $\begin{array}{c}\text { Duyguların } \\
\text { dürüstçe } \\
\text { ifade } \\
\text { edilmesi } \\
\text { teşvik } \\
\text { edilmektedir } \\
\text {. }\end{array}$ & $\begin{array}{c}\text { Kariyer } \\
\text { yapmak her } \\
\text { iki cinsiyet } \\
\text { içinde bir } \\
\text { seçenektir. }\end{array}$ & $\begin{array}{l}\text { Kariyer } \\
\text { yapmak } \\
\text { erkek için } \\
\text { zorunlu } \\
\text { kadın için } \\
\text { ise bir } \\
\text { seçenektir. }\end{array}$ & $\begin{array}{c}\text { Üst } \\
\text { yöneticiler } \\
\text { stratejilere } \\
\text { uğraşırlar. }\end{array}$ & $\begin{array}{l}\text { Üst yöneticiler } \\
\text { günlük işlerle } \\
\text { uğraşırlar. }\end{array}$ \\
\hline $\begin{array}{c}\text { Astlarla } \\
\text { deneticilerin } \\
\text { ilişkisi } \\
\text { pragmatiktir. }\end{array}$ & $\begin{array}{c}\text { Astlarla } \\
\text { denetimcilerin } \\
\text { ilişkisi } \\
\text { duygusaldır. }\end{array}$ & $\begin{array}{c}\text { Grup içi } \\
\text { müssterilere } \\
\text { çok daha iyi } \\
\text { davranılır. }\end{array}$ & $\begin{array}{l}\text { Her müşteri } \\
\text { aynı tavırları } \\
\text { görmektedir }\end{array}$ & $\begin{array}{c}\text { Profesyonel } \\
\text { bir görevde } \\
\text { çalışan } \\
\text { kadın sayısı } \\
\text { daha } \\
\text { fazladır. }\end{array}$ & $\begin{array}{l}\text { Profesyonel } \\
\text { bir görevde } \\
\text { çalışan } \\
\text { kadın sayısı } \\
\text { daha azdır. }\end{array}$ & $\begin{array}{l}\text { Bir sürü } \\
\text { yeni } \\
\text { marka } \\
\text { vardır. }\end{array}$ & $\begin{array}{l}\text { Çok az yeni } \\
\text { marka vardır. }\end{array}$ \\
\hline $\begin{array}{c}\text { İmtiyazlar ve } \\
\text { statü sembolleri } \\
\text { hoş karşılanmaz. }\end{array}$ & $\begin{array}{c}\text { İmtiyazlar ve } \\
\text { statü } \\
\text { sembolleri } \\
\text { normal hatta } \\
\text { popülerdir. }\end{array}$ & $\begin{array}{c}\text { İlişkiler } \\
\text { görevlerden } \\
\text { çok daha } \\
\text { ağır } \\
\text { basmaktadır }\end{array}$ & $\begin{array}{c}\text { Görevler } \\
\text { ilişkilerden } \\
\text { çok daha } \\
\text { ağır } \\
\text { basmaktadır }\end{array}$ & $\begin{array}{l}\text { İşin insancıl } \\
\text { olması } \\
\text { iletişim ve } \\
\text { işbirliği } \\
\text { aracilığıyla } \\
\text { gerçekleşir. }\end{array}$ & $\begin{array}{l}\text { İşin insancıl } \\
\text { olması iş } \\
\text { içeriğinin } \\
\text { zenginleşmesi } \\
\text { ile } \\
\text { gerçekleşir. }\end{array}$ & $\begin{array}{c}\text { Kararın } \\
\text { sürecine } \\
\text { odaklanırl } \\
\text { ar. }\end{array}$ & $\begin{array}{c}\text { Kararın içeriğine } \\
\text { odaklanırlar. }\end{array}$ \\
\hline \multirow[t]{2}{*}{$\begin{array}{c}\text { Bedensel iş } \\
\text { yapanlar ile ofis } \\
\text { çalışanları aynı } \\
\text { statüye sahiptir. }\end{array}$} & $\begin{array}{c}\text { Beyaz yakalı } \\
\text { çalışanlar, } \\
\text { mavi yakalı } \\
\text { çalışanlardan } \\
\text { daha } \\
\text { değerlidir. }\end{array}$ & & & $\begin{array}{l}\text { Tarım ve } \\
\text { hizmet } \\
\text { sektörlerinde } \\
\text { rekabet } \\
\text { vardır. }\end{array}$ & $\begin{array}{c}\text { Üretim ve } \\
\text { kimyasal } \\
\text { ürünler } \\
\text { sektörlerinde } \\
\text { rekabet } \\
\text { vardır. }\end{array}$ & $\begin{array}{c}\text { Girişimciler } \\
\text { kurallardan } \\
\text { bağımsız } \\
\text { hareket } \\
\text { eder. }\end{array}$ & $\begin{array}{c}\text { Girişimciler } \\
\text { mevcut kurallar } \\
\text { tarafından } \\
\text { kısıtlanır. }\end{array}$ \\
\hline & & & & & & $\begin{array}{c}\text { Kendi } \\
\text { işinde } \\
\text { çalışan } \\
\text { sayısı } \\
\text { azdır. }\end{array}$ & $\begin{array}{l}\text { Kendi işinde } \\
\text { çalışan sayısı } \\
\text { çoktur. }\end{array}$ \\
\hline
\end{tabular}

Kaynak: Hofstede ve diğerlerinden (2010) uyarlanmıştır.

\section{ARAŞTIRMANIN METODOLOJISİ}

\subsection{Araştırmanın Amacı}

Araştırmanın amacı, işletmelerin sürdürülebilir olmaları için ihtiyaç duyduğu devir planlarının, kültürden ve kültürü etkileyen gelenek ile göreneklerden etkilenip etkilenmediğinin tespit edilmesidir. $\mathrm{Bu}$ ana amaca bağlı olarak araştırmanın hipotezleri oluşturulmuştur. Bu amacin test edilmesinde ise Hofstede in kriterleri ve ölçeği dikkate alınmıştır,

\subsection{Araştırmanın Hipotezleri}

Araştırmanın amacına bağlı olarak belirlenen 4 hipotez vardır.

$H_{1:}$ Gelenek ve görenekler devir planın etkilemektedir.

$\mathrm{H}_{2}$ : Gelenek ve görenekler, kültürü etkilemektedir.

$H_{3}$ : Kültür, işletmenin devir planlamasını etkilemektedir.

H4: Gelenek ve görenekler, kültür aracılı̆̆ıyla işletmenin devir planım etkilemektedir. 
Çalışmanın araştırma modeli Şekil 1'deki gibidir.

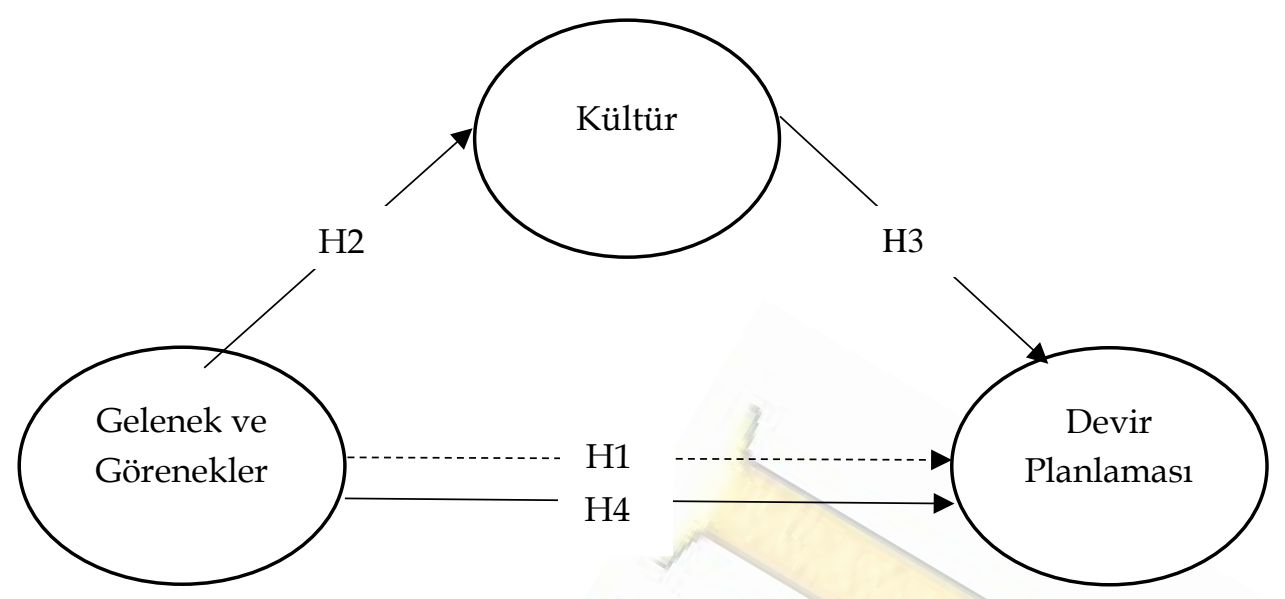

Şekil 1. Araştırma Modeli

Kaynak: Yazar tarafından üretilmiştir.

\subsection{Araştırmanın Evren ve Örneklemi}

Araştırmanın evreni, Konya ilinde faaliyet gösteren, hala aktif ve asgari faaliyet süresi 25 yıl olan aile işletmeleri olarak belirlenmiştir. Konya Sanayi Odası ve Konya Ticaret Odası veri kayıt tabanlarından elde edilen bilgiler eşliğinde bu kriterlere uyan firma sayısının 797 olduğu tespit edilmiştir. Tespit edilen bu evrene göre örneklem büyüklüğü, \%5 kabul edilebilir hata oranına göre \%95 güven aralığında 259 olarak hesaplanmıştır. Araştırmada oluşturulan modelin test edilebilmesi için "Yapısal Eşitlik Modelinden (YEM)" faydalanılmıştır. İlgili literatür incelendiğinde YEM için örneklem tespiti konusunda farklı görüşlerin olduğu belirlenmiştir. Gorsuch $(1983$, s. 332) her bir değişken için en az 5 örneklem ve toplamda en az 200 örneklem olması gerektiğini ifade ederken, Comfrey ve Lee (1992, s. 217) ise örneklem 201-300 aralığında yeterli olduğunu belirtmiştir. Her bir değişkene için 5 örneklem görüşü dikkate alındığında YEM için asgari örneklem sayısı 190 olarak hesaplanmıştır. Bu nedenle araştırma örneklemi 260 olarak belirlenmiştir. Böylelikle hem YEM analizi için asgari örneklem ile yeterli uyum gösteren örneklem sayısı şartı, hem de \%5 hata payında \% 95 güven aralığında gerekli olan 259 örneklem sayısı şartı sağlanmıştır. 


\subsection{Yöntem}

Araştırmada birincil veri toplama yöntemlerinden anket yöntemi tercih edilmiş ve veri toplamak için bir araştırma şirketinden yararlanılmıştır. Veri toplama sürecinde, araştırma şirketinin işini belirli standartlarda yapması için bir "Veri Toplama Teknik Şartnamesi" oluşturulmuş ve veri toplama sürecinin bu şartnameye göre yürütülmesine dikkat edilmiştir. Veriler toplanırken yüz yüze veri toplama yönteminden faydalanılmıştır. Ayrıca şirkete veri toplaması için evreni oluşturan 797 firmanın açık unvanı, sorumluları ve iletişim bilgilerinin de yer aldı̆̆ı "Anket Yapılabilecek İşletmelerin Listesi" de verilmiştir. Şirket listeye de uygun bir şekilde 260 işletmeden verileri toplamıştır. Araştırmaya katılan katılımcıların kaşelerinin bulunduğu anket formları araştırma şirketinden teslim alınmış ve araştırmanın yapılıp yapılmadığının teyidi için, tüm katılımcılar içinden rastgele seçilen katılımcılara telefon açılarak anketin yapılıp yapılmadığı tekrar kontrol edilmiştir.

Araştırmada kullanılan sorular, güvenilirliği ve geçerliliği sağlanmış mevcut literatür çalışmalarından (Atsu, 2016; Ogundele, Idris, Ahmed-Ogundipe, 2012) alınan ölçek ve sorulardan oluşmuş ve 5'li Likert tipi ölçek kullanılmıştır (1=Kesinlikle Katılmıyorum, 5=Kesinlikle Katılıyorum). Bu bağlamda, işletmelerin genel bilgilerinin elde etmeye yönelik 4 soru, kültür ölçeği için 8 değişken, gelenek ve görenekler ölçeği için 8 değişken ve devir planlamasını ölçeği için 8 değişken kullanılmıştır.

\section{ANALIZZ VE BULGULAR}

\subsection{Araştırmaya Katılan İşletmelerle İlgili Genel Bilgiler}

Tablo 2'de araştırmaya katılan işletmelerin sektör dağılımları, hukuki yapıları ve çalışan sayıları hakkında bilgilere yer verilmiştir.

Tablo 2' de gösterildiği üzere, araştırmaya toplam 260 işletme katılmış olup en çok katılımın sağlandığı sektör \% 81,5 oranıyla sanayi sektörü olmuştur. En az katılım ise \%3,8 oranıla tarım sektörüdür. Ayrıca bu işletmelerin \%25'i Anonim Şirket, \%75' $\mathrm{i}$ ise Limited Şirkettir. Çalışan sayısı incelendiğinde ise işletmelerin \% 43,8' $\mathrm{i}$ “110 çalışan sayısına", \% 28,8'i “11-50 çalışan sayısına”, \%23, 1'i “51-250 çalışan sayısına” ve \%4,2'si ise “251 ve üzeri çalışan sayısına” sahiptir. 
Tablo 2. Araştırmaya Katılan İşletmelerle İlgili Genel Bilgiler

\begin{tabular}{|c|c|c|}
\hline Sektör Ad1 & Sayı & Yüzde \\
\hline Sanayi & 212 & 81,5 \\
\hline Hizmet & 38 & 14,6 \\
\hline Tarım & 10 & 3,8 \\
\hline Toplam & $\mathbf{2 6 0}$ & $\mathbf{1 0 0}$ \\
\hline Hukuki Yap1 & Say1 & Yüzde \\
\hline Anonim Şirket & 65 & 25 \\
\hline Limited Şirket & 195 & 75 \\
\hline Toplam & $\mathbf{2 6 0}$ & $\mathbf{1 0 0}$ \\
\hline Çalışan Sayısı & Sayı & Yüzde \\
\hline 1-10 & 114 & 43,8 \\
\hline $11-50$ & 75 & 28,8 \\
\hline $51-250$ & 60 & 23,1 \\
\hline 251 ve üzeri & 11 & 4,2 \\
\hline Toplam & $\mathbf{2 6 0}$ & $\mathbf{1 0 0}$ \\
\hline & Kaynak: Yazar tarafından üretilmiștir. & \\
\hline
\end{tabular}

\subsection{Araştırmanın Analizler ve Bulguları}

Araştırmaya konu olan ölçeklerin, güvenilirlik katsayıları (Cronbach Alfa), AVE (Average Variance Excracted), CR (Composit Reliability), KMO (Kaiser-MeyerOlkin) ve Barlett değerleri, faktör yükleri, açımlayıcı faktör analizi sonuçları, toplam açıklanan varyans oranları, doğrulayıcı faktör analizi sonuçları (1. ve 2.) ve uyum iyiliği indeks sonuçları Tablo $3^{\prime}$ de gösterilmektedir. Çalışmaya öncelikle tüm ölçeklerin güvenilirlik katsayıları belirlenerek başlanmıştır. Bu süreçte Cronbach Alfa katsayından faydalanılmıştır. Tablo $3^{\prime}$ de gösterildiği üzere tüm ölçeklerin güvenilirlik katsayıları 0,94'ün üzerindedir. Ayrıca bu aşamada tüm ölçeklerin AVE ve CR değerlerine de bakılmıştır. Tabloda da görüldüğü üzere AVE ve CR değerleri istenilen değerlerin (CR için 0,70 ve AVE için 0,50) üzerindedir. Güvenilirlik katsayılarının ardından ölçekler, araştırma matrislerinin korelasyon düzeylerinin faktör analizine uygunluğunu test eden $\mathrm{KMO}$ ve Barlett testlerine tabi tutulmuştur. Uygunluk aranırken $\mathrm{KMO}$ değerinin 0,70'ten büyük olması, Barlett testinin ise p<0,005 şartını sağlaması gerekmektedir. Tablo 3'de tüm ölçeklere ait KMO ve Barlett değerleri verilmiştir. Tablo incelendiğinde tüm ölçeklerin değerlerinin faktör analizini yapmaya uygun olduğu görülmektedir. Bu sebeple açımlayıcı faktör analizine geçilmiştir.

Açımlayıcı faktör analizi yapılırken her bir değişkenin özdeğerinin (Eigen Value) 1'den büyük olmasına ve bu durumda faktör sayısının toplam varyansının 
2/3'ünü açıklamasına dikkat edilmiştir. Ayrıca faktör yüklerinin 0,50'den yüksek olmasına dikkat edilmiş olup bu değerden düşük olan değişkenler (Gelenek ve Görenekler" ölçeğinin 3. ve 6. Maddesi) ölçekten çıkarılmıştır. Analiz yapılırken dikkat edilen diğer bir husus ise her bir değişkenin tek bir faktörde yüksek yük değerine, diğer faktörde ise düşük yük değerine sahip olması beklenmiş ve her iki değer arasındaki farkı 0,40 oranı altında kalanlar ölçekten çıkarılmıştır. Açımlayıcı faktör analizi faktör yüklerinin ve açıklanan toplam varyans oranlarının araştırmaya devam etmek için uygun olduğu belirlenmiş ve doğrulayıcı faktör analizine geçilmiştir (bkz. Tablo 3). 
Tablo 3. Araştırmanın Analiz ve Bulguları

\begin{tabular}{|c|c|c|c|c|c|}
\hline \multirow{2}{*}{ Ölçekler } & \multirow{2}{*}{ Değişken } & \multicolumn{3}{|c|}{ Faktör Yükleri } & \\
\hline & & AFA & 1.DFA & 2.DFA & \\
\hline \multirow{8}{*}{ Kültür } & 1 & 0,82 & 0,84 & 0,84 & Cronbach a;95,6 \\
\hline & 2 & 0,88 & 0,91 & 0,91 & CR;0,95 \\
\hline & 3 & 0,84 & 0,86 & 0,86 & AVE;0,70 \\
\hline & 4 & 0,83 & 0,83 & 0,84 & \multirow{5}{*}{$\begin{array}{c}\text { KMO=0,96; } \\
\text { Barlett Sph. Testi = 1954,900; } \\
\text { Toplam Varyans= \%76,75; } \\
\text { Faktör Yükleri } \geq 0,50 .\end{array}$} \\
\hline & 5 & 0,86 & 0,87 & 0,86 & \\
\hline & 6 & 0,86 & 0,86 & 0,86 & \\
\hline & 7 & 0,85 & 0,86 & 0,86 & \\
\hline & 8 & 0,81 & 0,83 & 0,83 & \\
\hline \multirow{8}{*}{$\begin{array}{l}\text { Gelenek ve } \\
\text { Görenek }\end{array}$} & 1 & 0,62 & 0,67 & 0,68 & Cronbach $a ; 95,0$ \\
\hline & 2 & 0,66 & 0,69 & 0,70 & $\mathrm{CR} ; 0,81$ \\
\hline & 3 & 0,30 & - & - & AVE;0,51 \\
\hline & 4 & 0,63 & 0,63 & 0,63 & \multirow{5}{*}{$\begin{array}{c}\text { KMO=0,877; } \\
\text { Barlett Sph. Testi = 786,5850; } \\
\text { Toplam Varyans= \%70,26; } \\
\text { Faktör Yükleri } \geq 0,50 .\end{array}$} \\
\hline & 5 & 0,74 & 0,59 & 0,60 & \\
\hline & 6 & 0,43 & - & - & \\
\hline & 7 & 0,57 & 0,75 & 0,74 & \\
\hline & 8 & 0,64 & 0,88 & 0,88 & \\
\hline \multirow{8}{*}{$\begin{array}{l}\text { Devir } \\
\text { Planlamasi }\end{array}$} & 1 & 0,79 & 0,80 & 0,80 & Cronbach $a ; 94,2$ \\
\hline & 2 & 0,79 & 0,78 & 0,78 & CR;0,95 \\
\hline & 3 & 0,84 & 0,86 & 0,86 & AVE;0,70 \\
\hline & 4 & 0,84 & 0,85 & 0,85 & \multirow{5}{*}{$\begin{array}{c}\mathrm{KMO}=0,95 ; \\
\text { Barlett Sph. Testi =1577,928; } \\
\text { Toplam Varyans= \%71,11; } \\
\text { Faktör Yükleri } \geq 0,50 .\end{array}$} \\
\hline & 5 & 0,81 & 0,81 & 0,81 & \\
\hline & 6 & 0,82 & 0,84 & 0,84 & \\
\hline & 7 & 0,81 & 0,81 & 0,81 & \\
\hline & 8 & 0,80 & 0,80 & 0,80 & \\
\hline \multirow[t]{2}{*}{ Notlar } & \multicolumn{5}{|c|}{ (i) Varimax döndürme tekniği uygulanmıştır. } \\
\hline & \multicolumn{5}{|c|}{$\begin{array}{c}\text { (ii) Tüm Doğrulayıcı Faktör Analiz (DFA) sonuçları istatistiki olarak anlamlıdır } \mathrm{p}< \\
0.001\end{array}$} \\
\hline 1. DFA & \multicolumn{5}{|c|}{$\begin{array}{c}\mathrm{X} 2 / \mathrm{df}=1,364, \mathrm{GFI}=0,915 ; \mathrm{AGFI}=0,899 ; \mathrm{TLI}=0,984 ; \mathrm{CFI}=0,986, \mathrm{Pnf}_{1}=0,841, \\
\mathrm{RMSEA}=0,037\end{array}$} \\
\hline 2. DFA & \multicolumn{5}{|c|}{$\begin{array}{c}\mathrm{X} 2 / \mathrm{df}=1,272, \mathrm{GFI}=0,918 ; \mathrm{AGFI}=0,899 ; \mathrm{TLI}=0,987 ; \mathrm{CFI}=0,989, \mathrm{Pnf}_{1}=0,846, \\
\text { RMSEA }=0,032\end{array}$} \\
\hline
\end{tabular}

Kaynak: Yazar tarafından üretilmiştir.

Birinci düzey doğrulayıcı faktör analizi yapılırken öncelikle tüm veriler AMOS.24 programına aktarılmıştır. Ardından program aracılığıyla varyansların 1.00 'den yüksek ve standart regresyon ağırlığ1 değerlerinin 0,70' den düşük olan indis olup olmadığı kontrol edilmiş ve şartları sağlamayan değişkenler ölçekten çıkarılmıştır. Ancak ölçeklerde az bir farkla 0,70'in altında kalan değişkenler modelin genel uyumunu bozmadığı, ölçeğin anlamını yitirmemesi ve literatür açısından değerli katkıları olacağı öngörüsüyle ölçekten çıkarılmamıştır. 1. Düzey doğrulayıcı 
faktör analizinin ardından ikinci düzey doğrulayıcı faktör analizine geçilmiştir. Bu aşamada, her bir ölçeğe ait standart yük değeri verilmiş ve alt sınır olarak 0,50 değeri gözetilmiştir. Sonuç olarak tüm ölçeklerin istatistiki olarak uyumlu ve anlamlı olduğu sonucu bulunmuş olup ardından araştırma modelinin 1. ve 2. düzey doğrulayıcı faktör analizlerinin uyum indislerine bakılmıştır.

Tablo 3'de görüldüğü üzere, model uyum indeksleri iyi ve mükemmel seviyededir. Sonuç olarak model uyum iyiliği değerlerinin de geçerli olduğu görülmüş ve yapısal model aşamasına geçilmiştir.

\subsection{Yapısal Eşitlikte Yol Analizi}

İstenilen uyum değerleri sınırları içinde olan ölçüm modeli ve yapısal model yol analizi uygulanarak test edilmiştir. Burada amaç gizil değişkenler arasındaki ilişkinin tespit edilmesidir. Tablo 4 hipotezlerin değerlendirilmesini, Şekil 2 ise yol analizini göstermektedir.

Tablo 4. Araştırma Hipotez Sonuçları

\begin{tabular}{|l|c|c|c|c|c|}
\hline \multicolumn{1}{|c|}{ Hipotezler } & Ölçüm & S.E. & $\mathbf{t}$ & $\mathbf{p}$ & Sonuç \\
\hline $\begin{array}{l}\text { H1:Gelenek ve görenekler devir planını } \\
\text { etkilemektedir. }\end{array}$ & 0,11 & 0,218 & 0,415 & $\mathrm{p}>0,05$ & Ret \\
\hline $\begin{array}{l}\text { H2:Gelenek ve görenekler, kültürü } \\
\text { etkilemektedir. }\end{array}$ & 0,97 & 0,049 & 17,051 & $\mathrm{p}<0,001$ & Kabul \\
\hline $\begin{array}{l}\text { H3:Kültür, işletmenin devir planlamasını } \\
\text { etkilemektedir. }\end{array}$ & 0,80 & 0,255 & 3,148 & $\mathrm{p}<0,05$ & Kabul \\
\hline $\begin{array}{l}\text { H4: Gelenek ve görenekler, kültür } \\
\text { aracllığılyla işletmenin devir planını } \\
\text { etkilemektedir. }\end{array}$ & 0,88 & 0,055 & 13,930 & $\mathrm{p}<0,001$ & Kabul \\
\hline
\end{tabular}




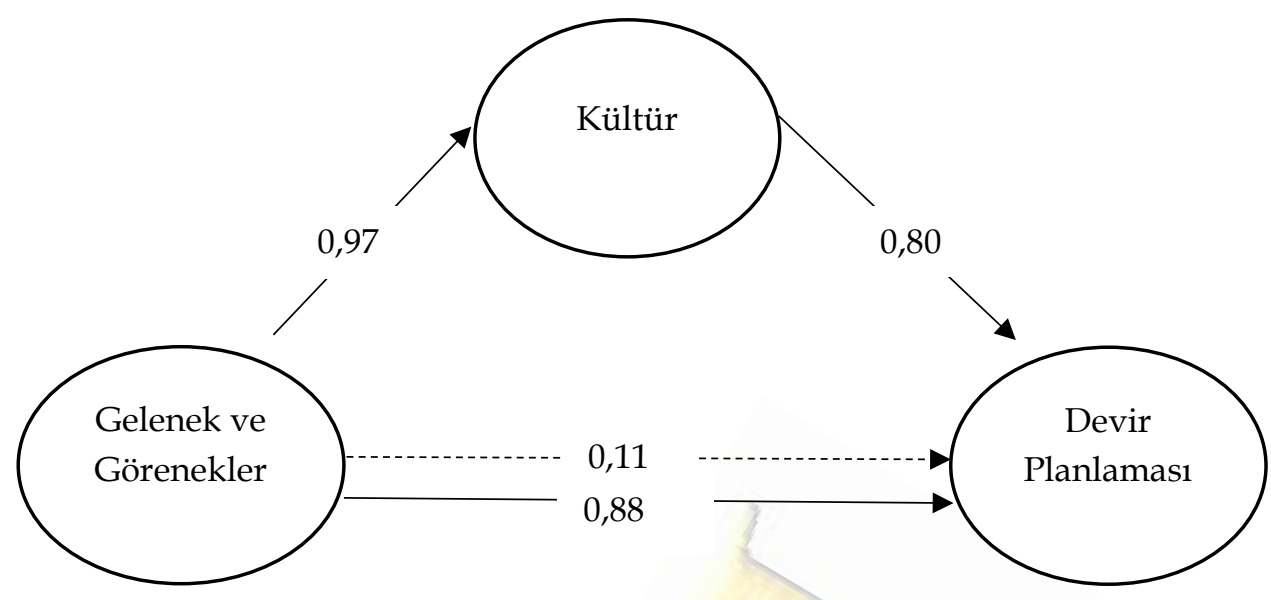

Şekil 2. Araştırma Modeli Yol Analizi

Kaynak: Yazar tarafından üretilmiştir.

Araştırma sonuçlarına göre $\mathrm{H} 2$, H3 ve $\mathrm{H} 4$ kabul edilmiş, $\mathrm{H} 1$ ise reddedilmiştir. Buna göre, gelenek ve görenekler, işletmelerin sürdürülebilir olmaları için ihtiyaç duyduğu devir planını doğrudan etkilememektedir. Ancak gelenek ve görenekler kültürü, kültür ise devir planını etkilemektedir. Ayrıca kültürün aracı değer kabul edilmesi ile yapılan analiz sonucunda gelenek ve göreneklerin devir planına dolaylı etki ettiği tespit edilmiştir.

\section{SONUÇ}

Birçok ülkenin temel ekonomik dinamiği ve tarihsel sürecin belirleyen aile işletmeleri, bölgesel kalkınmadan ulusal gelişmeye değin geniş bir etki alanına sahiptir. Bu sebeple bu işletmelerin gelişmesi ve sürdürülebilir olması, iç ve dış tüm ticari paydaşları doğrudan etkilemektedir. Ancak bu işletmelerin nesilden nesile devir edilirken kan kaybettiği de bilinen bir gerçektir. Bu süreçte aksini iddia edenler (Miller, 1993; Friedman, 1986) olsa da genel olarak literatürde, aile işletmelerinin etkili bir devir planlamasının olmasının sürdürülebilirlik ve kurumsal performansına olumlu katk1 yaptığ1 görüşü hâkimdir (Helmich, 1977; Trow, 1961; Kets de Vries, 1977; Handler, 1994; Harveston, Davis ve Lyden, 1997). Bu sebeple işletmeler için devir planlarının varlığı önemlidir. Ancak bu planlar hazırlanırken aile üyesi olmayan bağımsız kişi ve uzmanlardan yardım almak ve süreci objektif bir şekilde yürütmek de sürecin başarısı için çok kritiktir (Payne, 1999; akt. Huan, 1999, s. 738). Peki, bu süreç, işletmenin içinde bulunduğu anlık durumdan izole ve tarafsız bir şekilde yürütülebilmekte midir? Bu çalışma ülkemizde faaliyet gösteren işletmelerin 
sürekliliğine etki eden devir planlamasının, kurucunun oluşturduğu işletme kültürü ve kültürü etkileyen gelenek ve göreneklerden etkilenip etkilenmediğini belirlemek amacıyla yapılmıştır.

Araştırma sonucunda "Gelenek ve görenekler, kültürü etkilemektedir" şeklindeki Hipotez 2, "Kültür, işletmenin devir planlamasını etkilemektedir" şeklinde ki Hipotez 3 ve “Gelenek ve görenekler, kültür aracılığıyla işletmenin devir planını etkilemektedir" şeklindeki Hipotez 4 kabul edilmiş, “Gelenek ve görenekler, devir planını etkilemektedir" şeklindeki Hipotez 1 ise hipotezi reddedilmiştir.

Gelenek ve göreneklerin, kültürü oluşturan katmanlar arasında yer alan ve insanların nasıl davranması gerektiğini gösteren kurallar, normlar ve değerlerin oluşmasında çok büyük katkısı vardır (Schabracq, 2007, s. 17; Luthans ve Doh, 2012, s. 127). Bu sebeple Hipotez 2'nin kabul edilmesi literatürü destekleyen bir sonuç olmuştur.

Schein'e göre (1985), “ticari hayatın örgütleri, yani işletmeler kendiliğinden veya bir rastlantı sonucu oluşmazlar. Bunlar kurucu olan bir veya birkaç kişinin, toplu halde başarı sağlayacaklarını düşündükleri insanların faaliyetlerinin organize edilebileceğini algıladıkları için kurulurlar. Bu süreçte kurucular, işletmenin kendi içinde nasıl örgütleneceği, büyüme ve hayatta kalma gibi sorunlarının nasıl çözüleceği ve bir grubun tanımlanması gibi konularda çok büyük rol oynarlar. Çünkü kurucuların fikirlerini nasıl hayata geçirecekleri ile ilgili, temeli kendi kültürüne ve karakterine dayanan değerleri vardır. Böylelikle, işletmeler hayata geçtiği andan ömrünün sonuna kadar, kurucuların bu kültüre ve karaktere dayalı değerlerinin etkisi altında kalır ve kurucular bu varsayımların uygulanması için işletmesini yönlendirir. Yeni bir lider işletmeye katıldığında bu değerleri yeniden revize etse de bu değerler işletme kültürünün üstünde daime çok büyük etkiye sahip olacaktır" (akt. Frost Moore, Louis, Lundberg ve Martin, 1991, s. 14-15). Dolayısıyla, bir kurucunun işletmesine yaşadığı toplumun kültürünü ve karakteristik özelliklerini aktardığı, yeni nesillerin görevi devir almasına rağmen bu kültürün korunduğu ve dolayısıyla devir planlarının da bu kültürden etkilendiği sonucu çıkarılabilir. Kabul edilen Hipotez 3'de, bu görüşü desteklemektedir. 
Hipotez 1 ve Hipotez 4'e göre gelenek ve görenekler, devir planını doğrudan etkilememesine rağmen, bir aracı değer olarak modele kültür ölçeği dâhil edildiğinde, devir planını etkilediği tespit edilmiştir. İşletmenin genetiği kurucu tarafından işin en başında işletme kültürü aracılığıyla oluşturulur. Bu nedenle işletmenin geleceği yine bu kültürden etkilenecektir. Gelenek ve görenekler, kültürü etkileseler de kültürün tek yapı taşı olamazlar. Çünkü kültür dinamik bir olgudur ve yapı taşında çok farklı unsurları barındırmaktadır. Bu nedenle gelenek ve görenekler, işletmenin sürdürülebilirliğine etki eden devir planlamasını tek başına etkileyecek bir güce sahip değildir. Ancak kültürün çatısı altında bu planlamaya etki edebilirler. Atsu'da (2016, s. 181) benzer bir sonuç elde etmiş ve geleneklerin kültürel bir ürün olarak devir planını etkilediği sonucuna ulaşılmıştır. Hofstede'in (1980) ifade ettiği gibi ülkemiz güç aralı̆̆ı yüksek, kolektivist, dişil ve belirsizlikten yüksek oranda kaçınan bir kültüre sahiptir. Bu bağlamda ülkemizin iş kültürü; hiyerarşik ve merkeziyetçidir, üstler ile astlar arasında birçok unsur açısından (maaş, saygınlık vb.) çok büyük farklar görülür, denetimciler az ve katı kuralların çoktur, astlar iş yapmak için üstlerin emirlerini bekler, mesleki hareketlilik düşüktür, bireylerden çok gruplar önemlidir ve işe alma, terfi ve çıkarlar dâhil olunan gruplara göre değerlendirilir, ahlaki unsurlar ve ilişkiler çok önemlidir, stratejik karar alma sürecinde sezgi ve fikirler çok önemlidir, çatışmalar karşılıklı anlaşma yoluyla çözümlenir, yaşamak için çalışan insanlar vardır, çok fazla psikolojik kural vardır, meşgul olmak ihtiyacı ve çok fazla önlem vardır, az sayıda marka vardır, kendi işinde çalışan kişi sayısı çoktur şeklinde özellikler taşımaktadır (bkz. Tablo 1). Bu sonuçlar eşliğinde sorulması gereken iki temel soru vardır. İlki, devir planlamasının, gelenek, görenek ve kültürden etkilenmesi, planın başarılı bir şekilde yürütülmesi ve uygulanmasında bir soruna yol açar mi? İkincisi ise kurucunun kendi kültüründen etkilenerek oluşturduğu bu devir planı, gelecek nesillerce benimsenerek işletmenin performansı ve sürdürülebilirliğine olumlu etki eder mi? Çünkü bu süreçte anlık şartlardan izole ve objektif bir danışma kurulunun oluşturulması süreç için kritik bir adımdır. Sonuç olarak işletmelere, uzman bir danışma kurulunun oluşturulması ve sürecin tüm nesillerin fikirleri de alınarak objektif ve rasyonel şekilde yürütülmesi tavsiye edilmektedir. 
$\mathrm{Bu}$ çalışma gelenek, görenek ve kültürün işletmelerin devir planlamaları üzerindeki etkilerini incelemek için yapılmış ve bu yönüyle literatüre katkı sağlamıştır. Her araştırma da olduğu gibi bu araştırmanın da süre, örneklem büyüklüğü ve ekonomik şartlar açısından kısıtlılıkları vardır. Ayrıca elde edilen bulgular aracılığıyla, devir planının başarılı bir şekilde uygulanması, işletme performansı ve sürdürülebilirliği konuları açısından yeni bir araştırma konusu oluşturulabilir. 


\section{KAYNAKÇA}

Atsu, D.W. (2016). Culture And Management Transition Planning in Nigerian Family Businesses: Mixed Methods Study, Phoenix Üniversitesi, Doktora Tezi, ABD.

Bjuggren, P.O. ve Sund, L.G. (2001). Strategic Decision Making in Intergenerational Successions Of Small-And Medium-Size Family-Owned Businesses. Family Business Review, 14(1), 11-23.

Christensen, C. R. (1953). Management Succession in Small and Growing Enterprises. Boston: Harvard University Press.

Chua, J. H., Chrisman, J. J. ve Sharma, P. (1999). Defining The Family Business By Behavior. Entrepreneurship Theory and Practice, 23(4), 19-39.

Comfrey A.L. ve Lee H.B. (1992). A First Course in Factor Analysis. ABD: Hillsdale Lawrence Erlbaum Associates.

Deloitte, Akbank, Taider ve İstanbul Sabancı Üniversitesi (2016). Aile Şirketlerinde Sürdürülebilir Başarının Anahtarları, Erişim Adresi: https://www2.Deloitte.Com/Content/Dam/Deloitte/ $\operatorname{Tr} /$ Documents/Risk/Aile-Sirketlerinde Surdurulebilir-Basarinin-Anahtarlari.Pdf

Eren, E. (2001). Örgütsel Davranış ve Yönetim Psikolojisi. İstanbul:Beta.

European Family Business (EFB) (2018). Family Business Across Europe: Percentage Of Total Of Companies. Erişim Adresi: http://www.Europeanfamilybusinesses.Eu/Family-Businesses/FactsFigures

Friedman S.D. (1986). Succesion System in Large Corporation: Characteristics and Correlates of Performance. Human Resource of Management, 25(2), 191-213.

Frost, P. J., Moore, L. F., Louis, M. R., Lundberg, C. C. ve Martin, J. (1991). Reframing Organizational Culture. ABD: Sage Publications.

Godwyn, M., ve Gittell, J. H. (2011). Sociology of Organizations: Structures and Relationships. ABD: Sage Publications.

Gorsuch R.L. (1983). Factor Analysis (2. Bask1.). ABD: Hillsdale Lawrence Erlbaum Associates.

Handler, W. (1994). Succession in Family Business: A Review Of The Literature. Family Business Review, 7(2), 133157.

Harveston, P. D., Davis, P. S. ve Lyden, J. A. (1997). Succession Planning in Family Business: The Impact Of Owner Gender. Family Business Review, 10(4), 373-396.

Helmich, D. (1977). Executive Succession in The Corporate Organization: A Current Integration Academy of Management Review, 2(2), 252-266.

Hofstede, G., Hofstede, G. J. ve Minkov, M. (2010). Cultures And Organizations: Software Of The Mind. Revised And Expanded (3. Baskı). ABD: Mcgraw-Hill.

Huang, T. C. (2001).Succession Management Systems And Human Resource Outcomes. International Journal of Manpower, 22(8), 736-747.

Karadeniz, S. (2007).Gelenek Üzerine Bir Okuma Denemesi ‘Geçmişle Gelecek Arasında Gelenek'. Milel ve Nihal: İnanç, Kültür ve Mitoloji Araştırmaları Dergisi, 4(2), 29-47.

Kets De Vries, M. F. R. (1977). The Entrepreneurial Personality: A Person At The Crossroads. The Journal of Management Studies, 34-57.

Luthans, F., ve Doh, J. P. (2012). International Management: Culture, Strategy, and Behavior. New York: Mcgraw-Hill.

Miller, D. (1993). Some Organizational Consequences Of Ceo Succession. Academy Of Management Journal, 36 (3), 1-19. 
Ogundele, O. J. K., Idris, A. A. ve Ahmed-Ogundipe, K. A. (2012). Entrepreneurial Succession Problems in Nigeria's Family Businesses: A Threat To Sustainability. European Scientific Journal, 8(7). 208-227.

Pwc. (2016). Aile Şirketleri Araştırması. Erişim Adresi: https://Www.Pwc.Com.Tr/Tr/Hizmetlerimiz/ Aile-Sirketleri/Aile-Sirketleri-Arastirmasi-2016.Html

Schabracq, M. J. (2007). Changing Organizational Culture: The Change Agent's Guidebook. ABD: John Wiley \& Sons.

Score (2018). Infographic: The Family Business-Success And Obstacles. Erişim Adresi: https://Www.Score.Org/Resource/İnfographic-Family-Business-Successes-And-Obstacles (Erişim Tarihi: 05.02.2019).

Sharma, P., Chua, J. H. ve Chrisman, J. J. (2000). Perceptions About The Extent Of Succession Planning in Canadian Family Firms. Canadian Journal Of Administrative Sciences/Revue Canadienne Des Sciences De L'administration, 17(3), 233-244.

Şimşek, Ş. (2001). Yönetim ve Organizasyon (6.Baskı). Günay Ofset:Konya.

Trow, D. (1961). Executive Succession in Small Companies. Administrative Science Quarterly, 6, 228-239. Türk Dil Kurumu (TDK) (2020). Gelenek ve Göreneğin Tanımı. Erişim Adresi: https://Sozluk.Gov.Tr/? Kelime=İnan\%C3\%A71\%C4\%B1-Geleneksel (Erişim Tarihi: 02.02.2020). 